\title{
Macular puckers after retinal detachment surgery
}

\author{
W. S. HAGLER AND UPALI ATURALIYA*
}

From the Department of Ophthalmology, Emory University School of Medicine, and Emory University Clinic, Atlanta, Georgia

The term "macular pucker" describes the star-shaped folds and wrinkles which sometimes appear on or near the macula after surgery for retinal detachment, because of a localized area of preretinal membrane formation which contracts and causes wrinkling (Fig. I). The density of this membrane may vary, the least dense being that seen in the condition called "cellophane maculopathy" (Maumenee, 1967) (Fig. 2). These puckers, which

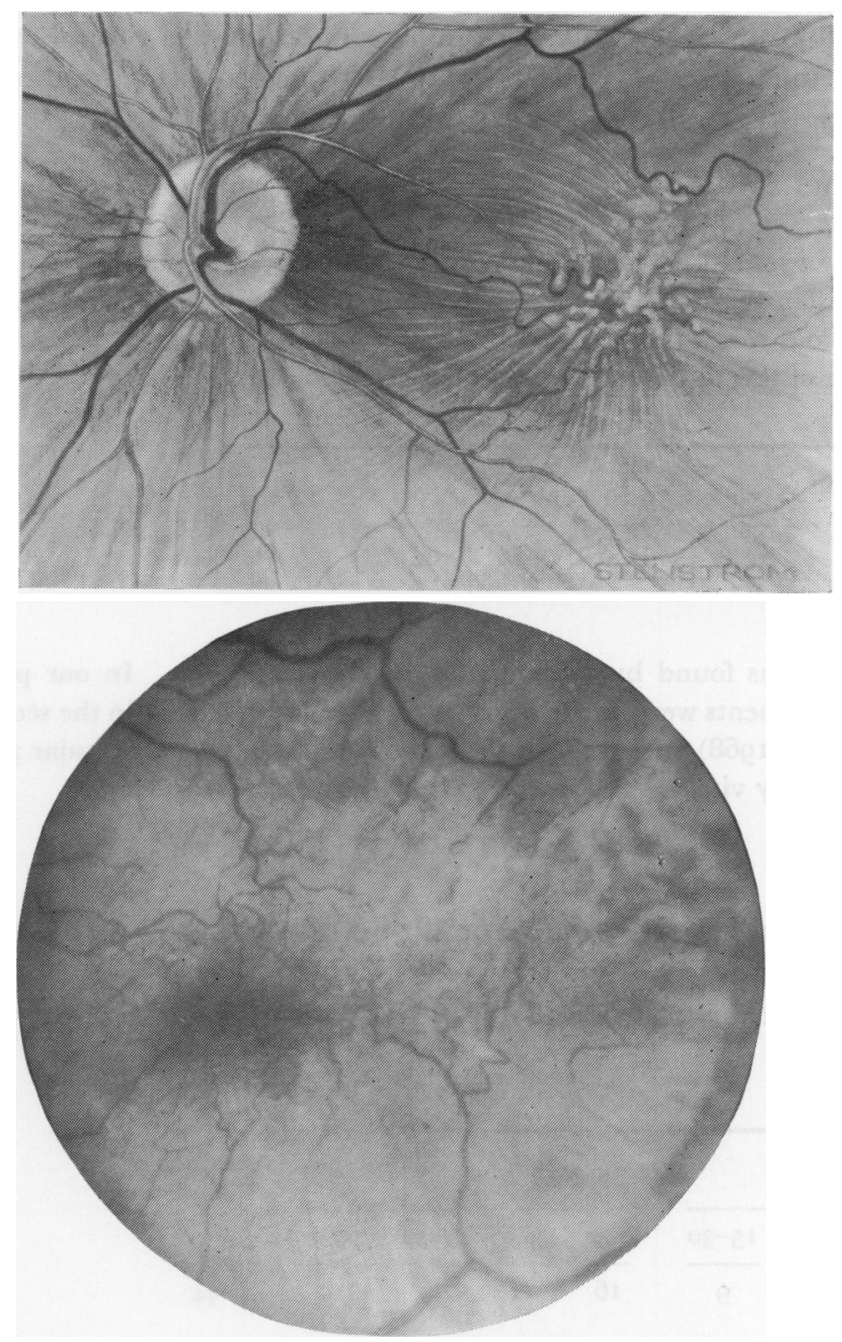

FIG. I Fundus drawing of $a$ macular pucker. Note area of preretinal organization with wrinkling of the retina, tortuosity of the vessels, and loss of the macular reflex with a greyish appearance of the macula

FIG. 2 Fundus photograph of a cellophane maculopathy. Note increased tortuosity of vessels at the macula with wrinkling of the retina and loss of the macular reflex 
have been described by Jungshaffer (1966) and Tanenbaum, Schepens, Elzeneiny, and Freeman (1970), are one of the most frequent causes of visual deterioration after successful reattachment of the retina (Sariu and Macdonald, I970), but may also appear spontaneously in eyes which have not undergone surgery.

Spontaneous puckers may be due to pathology of the retinal periphery, e.g. retinal breaks, especially in the upper temporal quadrant, inflammation of the pars plana, and vitreous loss due to trauma. Idiopathic cases are rare.

In cases in which puckers occur after surgery, there is usually a gradual improvement in the sight for 2 or 3 months after a successful reattachment of the retina, but then the patient suddenly notices blurred vision, and sometimes, especially if the visual acuity is good, metamorphosia and entoptic phenomena. At this stage, the observer may see only a haziness over the macular region, but this picture quickly changes, usually within about 2 days. The vision drops precipitously and a diaphanous, greyish-white membrane may be seen overlying the macula. The edges of the membrane are sometimes seen to fuse with the posterior surface of the detached virteous. This is an alarming situation for the patient as well as for the ophthalmologist, especially if the patient had a visual acuity of $20 / 20$ before an operation involving only the photocoagulation of a retinal tear.

It is the purpose of this paper to examine predisposing factors in the development of this condition, including the methods of reattaching the retina.

\section{Material}

In a series of 1,07 I cases of retinal detachment at Emory University Hospital, 44 ( 16 males and 28 females) developed macular pucker. The numbers of phakic (23) and aphakic (2I) eyes were almost equal. In a previous series (Hagler, Jarrett, and Presley, 1970), only 30 per cent. of cases were aphakic. The ages of the 44 patients were as follows:

\begin{tabular}{lllllll}
\hline Age group $(y r s)$ & $\frac{1-40}{1}$ & $\frac{41-50}{5}$ & $\frac{51-60}{17}$ & $\frac{61-70}{14}$ & $\frac{71+}{7}$ & $\frac{\text { Total }}{44}$ \\
\hline
\end{tabular}

A similar age distribution was found by Tanenbaum and others (1970). In our previous series, Io per cent. of retinal detachments were due to anterior dialysis and occurred in the second and third decades (Hagler and North, 1968), but none of these patients developed a macular pucker, which indicates that a young healthy vitreous is not easily affected by retinal tears.

\section{Observations}

Nine of the retinal detachments were situated on the macula and 35 away from the macula. 0 In fifteen cases there was vitreous haemorrhage.

The lapse of time between surgery and the development of a macular pucker in our $\mathrm{C}$ 44 cases is shown below:

\begin{tabular}{|c|c|c|c|c|c|c|c|c|}
\hline \multirow{2}{*}{ Interval } & \multicolumn{3}{|c|}{ Days } & \multicolumn{4}{|c|}{ Months } & \multirow{2}{*}{ Total } \\
\hline & $\mathrm{I}-7$ & $8-14$ & $15-30$ & $I-2$ & $3-6$ & $7-12$ & $12+$ & \\
\hline No. of cases & 2 & 2 & 9 & 16 & I I & 2 & $\mathbf{I}$ & 44 \\
\hline
\end{tabular}


Tanenbaum and others (1970) reported a similar lapse of time, usually 2 to 3 months. A distinction may be made between paramacular and macular puckers, because a greater degree of visual acuity may be retained with the former. Examples of the former are shown in Figs 3 to 5 and of the latter in Fig. 6.

(3)

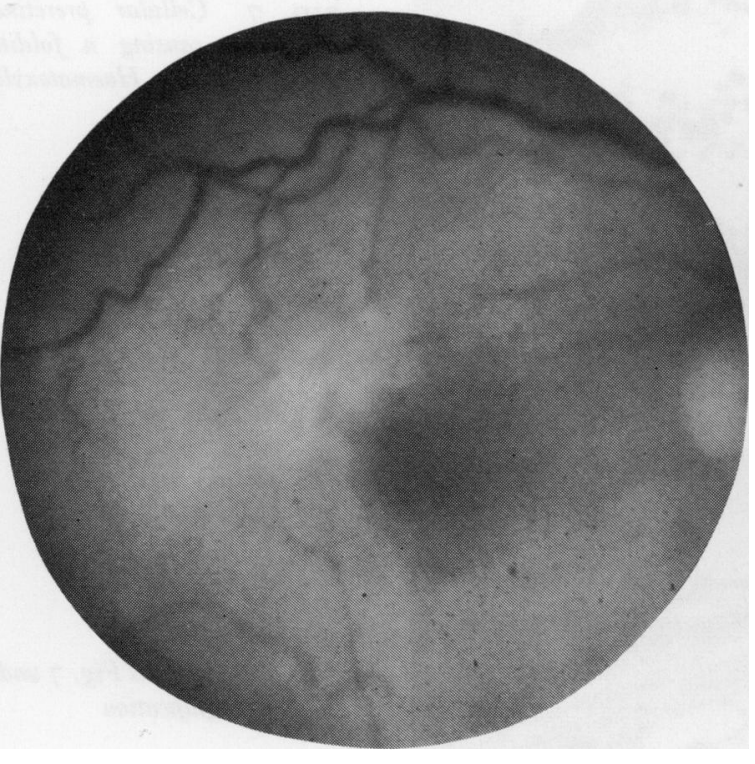

(5)

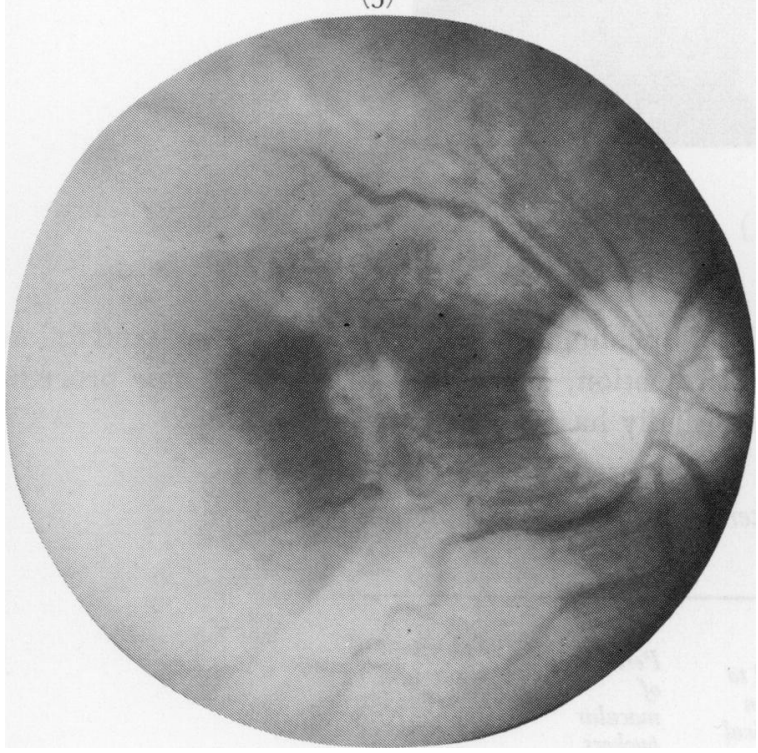

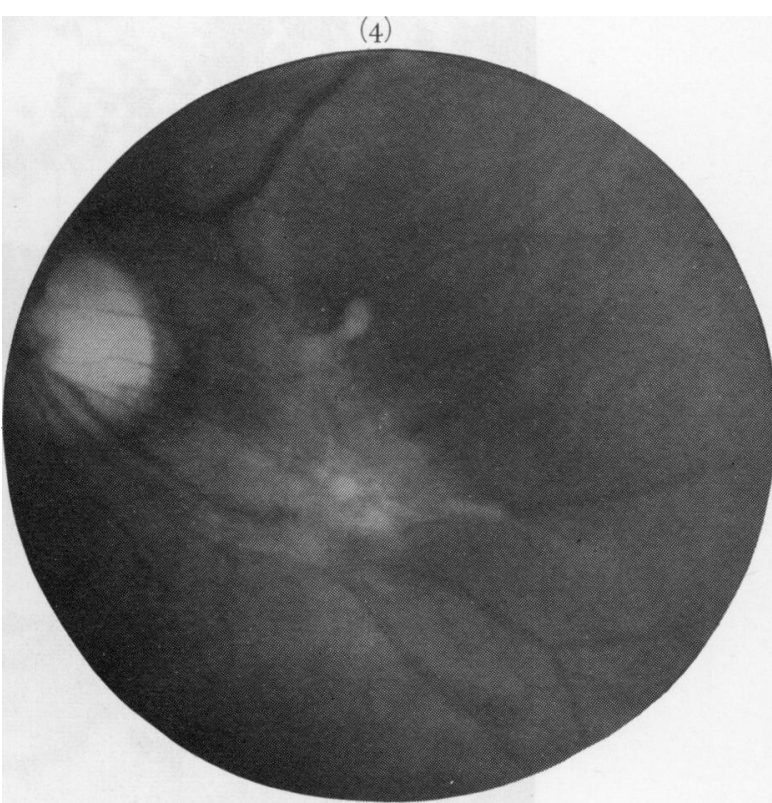

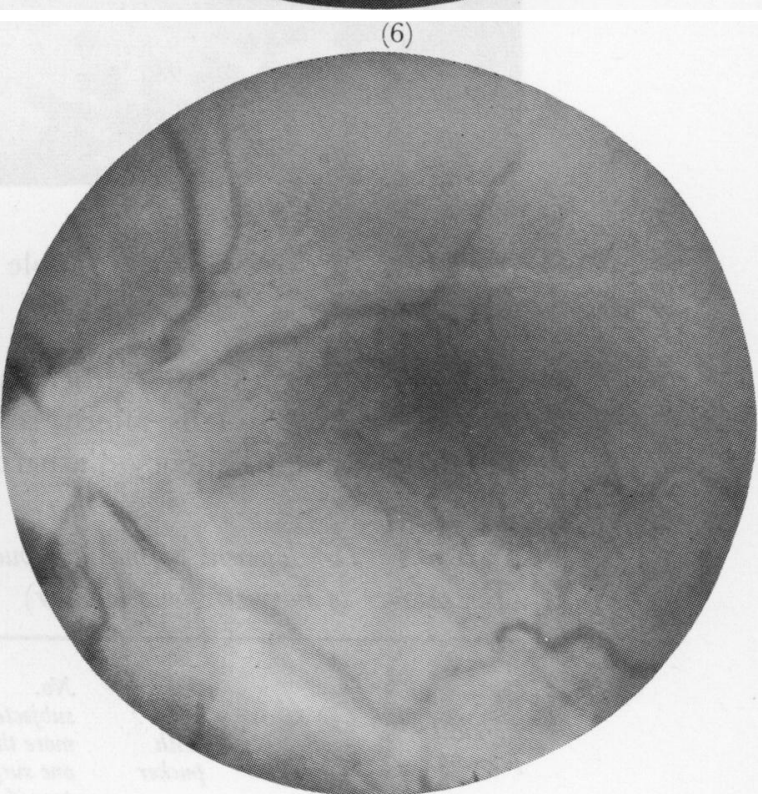

FIGS 3, 4, 5 Fundus photographs of three cases of paramacular pucker. Note area of preretinal organization adjacent to macula.

FIG. 6 Very advanced stage of a macular pucker.

Histological sections are shown in Figs 7 and 8 (overleaf). 


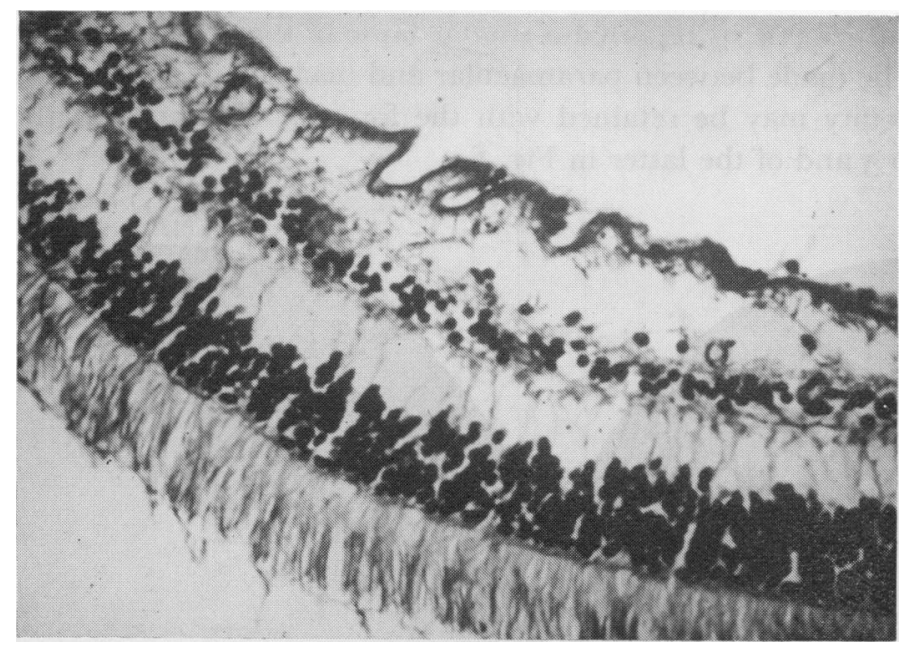

FIG. 7 Cellular preretinal membrane causing a folding of the retina. Haematoxylin and eosin. $\times 90$

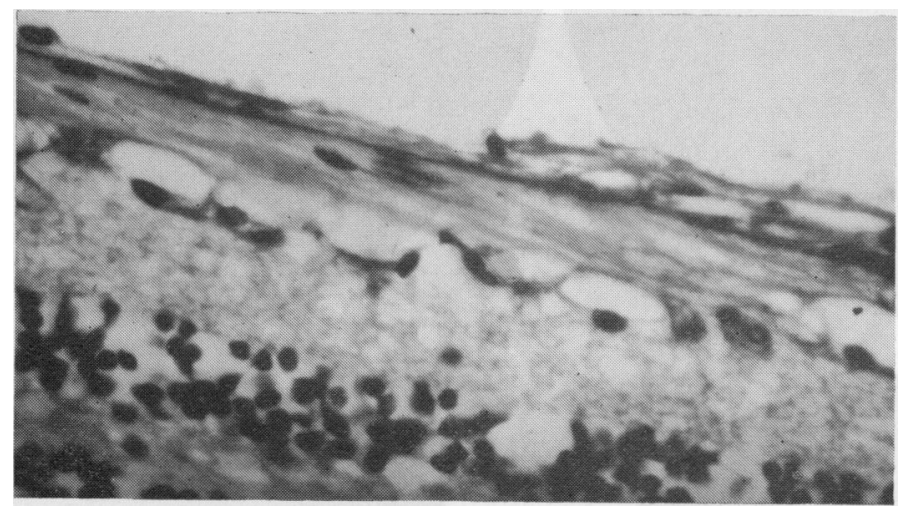

FIG. 8 Same as Fig. 7 under higher magnification

SURGICAL PROGEDURES (Table I)

\section{Diathermy}

The operation consisted of either a scleral buckling procedure with a silicone band followed by a diathermy, usually after a scleral resection, or a localized Custodis type procedure. The Mira radio frequency diathermy usually has an intensity setting of 40 .

Table I Development of macular puckers related to surgical procedure (percentages to nearest whole number)

\begin{tabular}{|c|c|c|c|c|c|}
\hline $\begin{array}{l}\text { Surgical } \\
\text { procedure }\end{array}$ & $\begin{array}{l}\text { No. } \\
\text { of } \\
\text { cases }\end{array}$ & $\begin{array}{l}\text { No. } \\
\text { with } \\
\text { pucker }\end{array}$ & $\begin{array}{l}\text { No. } \\
\text { subjected to } \\
\text { more than } \\
\text { one surgical } \\
\text { procedure }\end{array}$ & $\begin{array}{l}\text { Percentage } \\
\text { of } \\
\text { macular } \\
\text { puckers }\end{array}$ & $\begin{array}{l}\text { Percentage of } \\
\text { puckers in } \\
\text { those having } \\
\text { only one } \\
\text { procedure }\end{array}$ \\
\hline Total & 1071 & 44 & 14 & 9 & 6 \\
\hline Diathermy & $3^{22}$ & 17 & 4 & 5 & 4 \\
\hline Cryopexy & 749 & 26 & 10 & 3 & 2 \\
\hline
\end{tabular}




\section{Cryopexy}

The procedure is similar, the only difference being that we use diathermy to mark and localize the posterior edge of the tear, which is then surrounded by a single or double row of cryopexy, with either an encircling procedure or a localized external silicone implant.

Of a total of 1,071 patients, 322 (30 per cent.) had diathermy, and seventeen ( 5 per cent.) developed a macular pucker. In the cryopexy group of 749 patients ( 70 per cent.), 26 (3 per cent.) developed a macular pucker. When one considers the number of procedures used for each patient this becomes more interesting.

Of the 26 cases undergoing cryopexy, ten had had two procedures; i.e. sixteen patients had only one cryopexy, which reduces the number with puckers to 2 per cent.

Of the seventeen cases undergoing diathermy, four had had more than one procedure; i.e. thirteen patients had had only one diathermy, which reduces the number with puckers to 4 per cent. (Table II).

Table II Comparison of preoperative and postoperative visual acuity in 44 cases

\begin{tabular}{|c|c|c|c|c|c|c|c|c|}
\hline \multirow{2}{*}{$\begin{array}{l}\text { Preoperative } \\
\text { visual acuity }\end{array}$} & \multicolumn{7}{|c|}{ Best recorded postoperative visual acuity } & \multirow{2}{*}{$\begin{array}{r}\begin{array}{c}\text { Total } \\
\text { cases }\end{array} \\
\\
44\end{array}$} \\
\hline & $\begin{array}{l}20 / 15 \\
20 / 30\end{array}$ & $\begin{array}{l}20 / 40 \\
20 / 50\end{array}$ & $\begin{array}{l}20 / 60- \\
20 / 100\end{array}$ & $\begin{array}{l}20 / 200- \\
20 / 400\end{array}$ & $\begin{array}{l}\text { Counting } \\
\text { fingers }\end{array}$ & $\begin{array}{l}\text { Hand } \\
\text { move- } \\
\text { ments }\end{array}$ & $\begin{array}{l}\text { Percept- } \\
\text { ion of } \\
\text { light }\end{array}$ & \\
\hline $20 / 15^{-20} / 30$ & $\mathbf{I}$ & 2 & 2 & 2 & $\mathbf{I}$ & - & $\mathbf{I}$ & 9 \\
\hline $20 / 40-20 / 50$ & - & & $\mathbf{I}$ & - & - & - & - & I \\
\hline $20 / 60-20 / 100$ & - & - & & - & $\mathbf{I}$ & - & - & $\mathbf{I}$ \\
\hline $20 / 200-20 / 400$ & - & 2 & 2 & 6 & - & - & - & 10 \\
\hline Counting fingers & I & - & $\mathbf{I}$ & 2 & 3 & - & - & 7 \\
\hline Hand movements & - & I & - & 6 & 3 & & I & II \\
\hline Perception of light & - & - & - & 2 & 2 & I & & 5 \\
\hline
\end{tabular}

To find the significance of these values, we used the computer to apply Fisher's Exact Test on a $2 \times 2$ table. The results show one-tail significance at the $0 \cdot 05$ level for the numerical difference between patients having one cryopexy procedure and patients having one diathermy procedure.

\section{OUTCOME}

Once a pucker is formed it does not usually progress and does not alter with further surgery. The visual improvement varies depending on whether the pucker is macular or paramacular, and it usually does not progress to $M V R$. 
In our series of 44 cases (Table II), 23 per cent. improved, 23 per cent. became worse, and the remaining 54 per cent. were unchanged. This appears to be a hopeful prognosis, but unfortunately the visual acuity before operation may be as good as 20/15, as in the nine cases in the top row of the Table. The following case illustrates this possibility.

\section{Case report}

A 50-year-old white female was seen in the Emory University Clinic on November 1 7, 1969, with a history of flashing lights and floaters of 9 days' duration.

\section{Examination}

The visual acuity was $20 / 25$ in the right eye and 20/20 in the left. Applanation tensions were $16 \mathrm{~mm} . \mathrm{Hg}$ in the right eye and $18 \mathrm{~mm} . \mathrm{Hg}$ in the left. The ocular adnexae were normal. Indirect ophthalmoscopy showed a subclinical retinal detachment in the upper nasal quadrant of the left eye (Fig. 9).

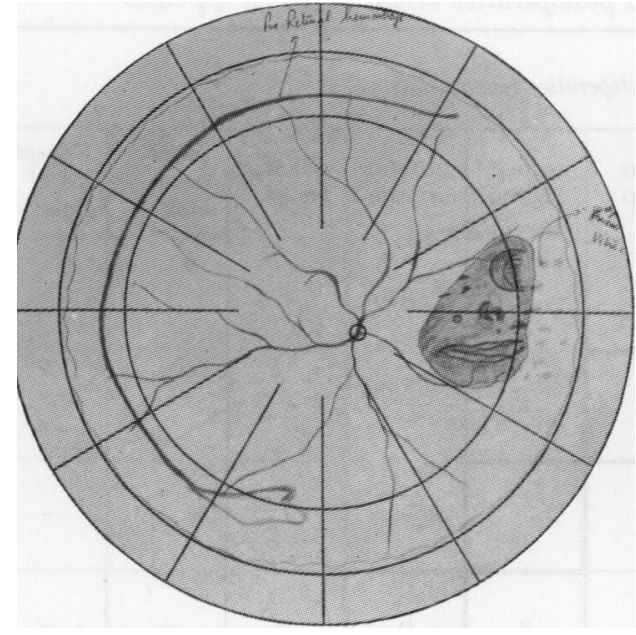

FIG. 9 Fundus drawing, showing preoperative state of left fundus (November I7, I 969 )

\section{Operation}

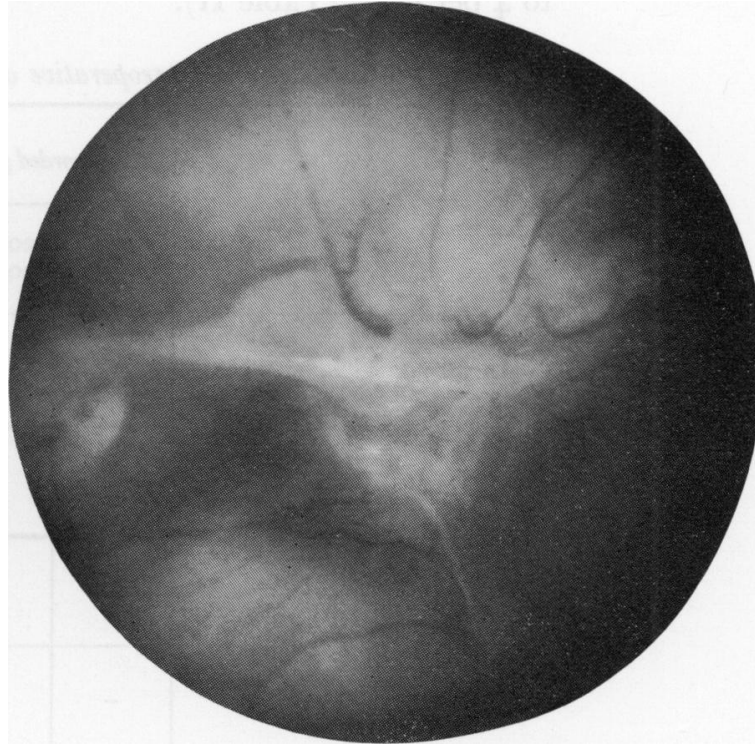

FIG. Io Fundus photograph. Note area of preretinal organization over the macula representing a macular pucker (December 29, 1969)

She was admitted to Emory University Hospital on November 9, and underwent a scleral buckling procedure with an external silicone sponge implant with cryopexy of the tear and drainage of subretinal fluid at two sites, followed by paracentesis of the anterior chamber.

\section{Result}

She was examined daily with the indirect ophthalmoscope and was found to have residual fluid on the buckle which disappeared on about the 9 th day. On the I Ith postoperative day, since there was inadequate pigmentation of the posterior edge of the tear, she was treated with the Zeiss photocoagulator set at Green III, 4.5-0. She was discharged from the hospital 2 days later.

\section{Follow-up}

On December 15, she had 20/20 vision in the left eye, but one week later she suddenly complained of decreased vision with metamorphopsia, and on December 29 she was found to have a macular pucker (Fig. 10).

Fig. I I (opposite) shows the progress of the visual acuity in graphic form after the development of the pucker. 


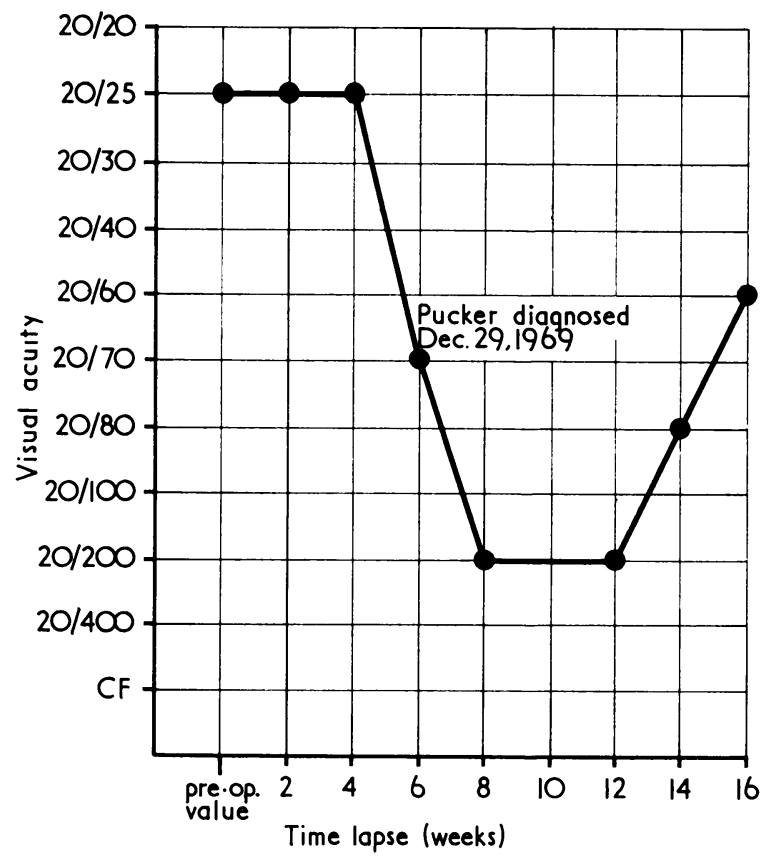

FIG. I I Visual results in a patient with macular pucker

\section{Summary}

Macular pucker usually occurs in patients over the age of 50 , usually between 50 and 60 years, after surgery for a retinal detachment of very short duration. Those with vitreous haemorrhage and vitreous membranes have a 25 to 30 per cent. chance of developing a pucker. In our series the type of surgery had a definite bearing on the formation of a macular pucker. Some of our patients were treated with steroids after the diagnosis of a macular pucker, but these were found to be of no value either in removing the pucker or in improving the vision.

The formation of macular puckers may be minimized in the following ways:

(I) Careful preoperative investigation to ensure that all retinal tears are discovered.

(2) The use of the least possible number of surgical procedures in reattaching the retina.

(3) The use of cryopexy rather than diathermy.

The authors express their thanks to Dr. William H. Jarrett, II, for the use of his medical records and his invaluable advice during the preparation of this paper, and to Dr. William R. Green, Johns Hopkins Hospital, Baltimore, Maryland, for the use of the two slides, Figures 7 and 8.

\section{References}

HAGler, w. S., JARrett, W. H., and Presley, G. D. (1970) J. med. Ass. Ga., 59, I02 - and NORTh, A. w. (I968) Arch. Ophthal. (Chicago), 79, 376

JUNGSGhafFer, O. H. (1966) Trans. pacif. Cst oto.-ophthal. Soc., 47, 65

maumenee, A. E. (I967) Arch. Ophthal. (Chicago), 78, I 5 I

Sarin, L. K., and mcdondal, P. R. (i970) Trans. Amer. Acad. Ophthal. Otolaryng., 74, 75

tanenbaum, H. L., schepens, c. l., elezneiny, i., and freeman, h. mack, (i97o) A.M.A. Arch.

Ophthal., 83, 286 